\title{
Testing for complementarity and substitutability in case of multiple practices
}

Citation for published version (APA):

Lokshin, B., Carree, M. A., \& Belderbos, R. A. (2004). Testing for complementarity and substitutability in case of multiple practices. METEOR, Maastricht University School of Business and Economics. METEOR Research Memorandum No. 002 https://doi.org/10.26481/umamet.2004002

Document status and date:

Published: 01/01/2004

DOI:

10.26481/umamet.2004002

Document Version:

Publisher's PDF, also known as Version of record

\section{Please check the document version of this publication:}

- A submitted manuscript is the version of the article upon submission and before peer-review. There can be important differences between the submitted version and the official published version of record.

People interested in the research are advised to contact the author for the final version of the publication, or visit the DOI to the publisher's website.

- The final author version and the galley proof are versions of the publication after peer review.

- The final published version features the final layout of the paper including the volume, issue and page numbers.

Link to publication

\footnotetext{
General rights Owners
rights.

- You may freely distribute the URL identifying the publication in the public portal. please follow below link for the End User Agreement:

www.umlib.nl/taverne-license

Take down policy

If you believe that this document breaches copyright please contact us at:

repository@maastrichtuniversity.nl

providing details and we will investigate your claim.
}

Copyright and moral rights for the publications made accessible in the public portal are retained by the authors and/or other copyright owners and it is a condition of accessing publications that users recognise and abide by the legal requirements associated with these

- Users may download and print one copy of any publication from the public portal for the purpose of private study or research.

- You may not further distribute the material or use it for any profit-making activity or commercial gain

If the publication is distributed under the terms of Article $25 \mathrm{fa}$ of the Dutch Copyright Act, indicated by the "Taverne" license above, 


\title{
Testing for complementarity and substitutability in case of multiple practices*
}

\author{
Boris Lokshin $^{\mathrm{a}}$, Martin Carree ${ }^{\mathrm{a}}$, and René Belderbos ${ }^{\mathrm{b}}$
}

\begin{abstract}
A number of recent empirical studies of firm-level productivity (growth) have been concerned with establishing potential complementarity between multiple organizational design practices. These papers have drawn conclusions on basis of the effect of the interaction term between each possible pair of practices. In this paper we show that this approach may lead to misleading results in case more than two practices are considered. We develop a proper testing procedure for complementarity and substitutability in case there are multiple organizational practices that affect output. The testing methodology is illustrated by empirical examples of three and four innovation practices affecting productivity. The testing framework can easily be applied to test for supermodularity.
\end{abstract}

Keywords: Complementarity; Supermodularity; Innovation JEL-code: C12; D24; $\mathrm{O} 31$

\section{Corresponding Author}

Prof.dr. Martin Carree

Department of Organization and Strategy

Faculty of Economics and Business Administration

Universiteit Maastricht

PO Box 616, 6200 MD Maastricht

The Netherlands

Phone: +31 433884981

Fax: +31 433254893

M.Carree@os.unimaas.nl

${ }^{\mathrm{a}}$ Universiteit Maastricht

${ }^{\mathrm{b}}$ Katholieke Universiteit Leuven and Universiteit Maastricht

\footnotetext{
* The empirical part of this research has been performed at CEREM/Statistics Netherlands. The views expressed
} in this paper are those of the authors and do not necessarily reflect the policies of Statistics Netherlands. 


\title{
Testing for complementarity and substitutability in case of multiple practices
}

\begin{abstract}
A number of recent empirical studies of firm-level productivity (growth) have been concerned with establishing potential complementarity between multiple organizational design practices. These papers have drawn conclusions on basis of the effect of the interaction term between each possible pair of practices. In this paper we show that this approach may lead to misleading results in case more than two practices are considered. We develop a proper testing procedure for complementarity and substitutability in case there are multiple organizational practices that affect output. The testing methodology is illustrated by empirical examples of three and four innovation practices affecting productivity. The testing framework can easily be applied to test for supermodularity.
\end{abstract}

Keywords: Complementarity; Supermodularity; Innovation

JEL-code: C12; D24; O31 


\section{Introduction}

Researchers in the fields of industrial organization and management have long been interested in investigating whether there exist complementary relations between various organizational practices of a firm. Complementarity is understood in this context to exist if the implementation of one practice increases the marginal or incremental return to other practices. Thus a joint implementation of several practices may result in economies of scope in a sense proposed by Baumol et al. (1988). By the same token the implementation of one practice can decrease the marginal or incremental return to other practices. This is the case of substitutability. Examples of studies of complementarity in the economics and management literature are the relationships between human resource practices and firm strategy (Ichniowski et al., 1997), firms' internal R\&D and external technology sourcing (Arora and Gambardella, 1994), different government innovation policies (Mohnen and Röller, 2002), information technology, workplace reorganization, and new product and service innovations (Bresnahan et al, 2002), and the adoption of different information technologies in emergency health care (Athey and Stern, 2002).

There are two econometric approaches that can be used to test for complementarity (Athey and Stern, 1998). The correlation approach (also coined 'adoption' approach) has been by far the most popular among empirical researchers due to its simplicity (Arora, 1996). The adoption approach tests conditional correlations based on the residuals of reduced form regressions of the practices of interest on all observable exogenous variables. However, although this test can serve as supportive evidence of complementarity if practices are adopted simultaneously (i.e. positive correlation), it cannot serve as a definitive test. Estimated correlations between residual terms may be the result of common omitted exogenous variables or measurement errors. Even in case of robust correlation between practices, there is no guarantee that decision markers were sufficiently well informed such that they indeed chose efficiency or output enhancing combinations of practices.

The only conclusive test for complementarity or substitutability is based on the 'production function' approach, in which organizational performance is related to exclusive combinations of organizational practices. This approach has been used in recent empirical work testing for complementarity between two practices (e.g. Veugelers and Cassiman, 2003), in which case a complementarity or substitutability test is a simple one-tailed t-test on the interaction variable. However, no robust testing procedure has been available to test for complementarity or substitutability with more than two practices, which has prevented a wide use of the production function approach in applied empirical work. Recent papers examining more than two practices have attempted to circumvent the problem by 
estimating pair-wise interaction effects, ignoring the interaction with other practices (Athey and Stern, 2002; Bresnahan et al., 2002, Caroli and Van Reenen, 2001). However, a proper complementarity or substitutability test requires testing for multiple inequality restrictions.

In this paper we propose a testing procedure of complementarity and substitutability that can be used in case of multiple (more than two) practices. It is based on the multiple inequality restriction-testing framework developed by Kudô (1963) and Wolak (1989). We discuss the cases of continuously measured practices as well as the case of dichotomous practices, which has been particularly relevant in most empirical applications. The analytical solution and an empirical application are demonstrated for the case of three and four practices. A first empirical example concerns complementarity or substitutability in product, process and organizational innovation and their impact on labour productivity. A second empirical example concerns complementarity or substitutability in four different types of $R \& D$ cooperation strategies.

\section{Complementarity and substitutability}

This section describes the definitions and conditions concerning complementarity and substitutability both for the case of continuously measured practices and the case of dichotomous practices. Consider an objective function $f$ of which the value is determined by the practices $x_{p}(p=1, \ldots, n)$. In case the practices are measured continuously the following definition of complementarity holds (e.g. Baumol et al., 1988):

\section{Definition 1 (continuous practices)}

Practices $x_{i}$ and $x_{j}$ are considered complementary in the function $f$ if and only if $\partial^{2} f / \partial x_{i} \partial x_{j}$ is always larger or equal to zero and larger than zero for at least one value of $\left(x_{1}, \ldots, x_{n}\right)$.

The definition for substitutability is identical as definition 1 except that 'larger' is replaced by 'smaller'. We use a cross-term specification of the objective function $f$ to test for complementarity or substitutability. The expressions for $n$ equal to 2, 3 and 4 are:

$$
\begin{aligned}
& f\left(x_{1}, x_{2}\right)=\alpha_{0}+\alpha_{1} x_{1}+\alpha_{2} x_{2}+\alpha_{12} x_{1} x_{2} \\
& f\left(x_{1}, x_{2}, x_{3}\right)=f\left(x_{1}, x_{2}\right)+\alpha_{3} x_{3}+\alpha_{13} x_{1} x_{3}+\alpha_{23} x_{2} x_{3}+\alpha_{123} x_{1} x_{2} x_{3} \\
& f\left(x_{1}, x_{2}, x_{3}, x_{4}\right)=f\left(x_{1}, x_{2}, x_{3}\right)+\alpha_{4} x_{4}+\alpha_{14} x_{1} x_{4}+\alpha_{24} x_{2} x_{4}+\alpha_{34} x_{3} x_{4}+
\end{aligned}
$$




$$
+\alpha_{124} x_{1} x_{2} x_{4}+\alpha_{234} x_{2} x_{3} x_{4}+\alpha_{1234} x_{1} x_{2} x_{3} x_{4}
$$

The cross-derivatives $\partial^{2} f / \partial x_{1} \partial x_{2}$ are equal to $\alpha_{12}$ for equation (1), $\alpha_{12}+\alpha_{123} x_{3}$ for equation (2) and $\alpha_{12}+\alpha_{123} x_{3}+\alpha_{124} x_{4}+\alpha_{1234} x_{3} x_{4}$ for equation (3), respectively. This implies that there is complementarity for the case of practices 1 and 2 if $\alpha_{12}>0$. In case of three practices, $\alpha_{12}+\alpha_{123} \min \left(x_{3}\right) \geq 0$ and $\alpha_{12}+\alpha_{123} \max \left(x_{3}\right) \geq 0$ should hold with at least one of the inequalities holding. In case of four practices there are four inequalities of which at least one should hold strictly:

$\alpha_{12}+\alpha_{123} \min \left(x_{3}\right)+\alpha_{124} \min \left(x_{4}\right)+\alpha_{1234} \min \left(x_{3}\right) \min \left(x_{4}\right) \geq 0$,

$\alpha_{12}+\alpha_{123} \min \left(x_{3}\right)+\alpha_{124} \max \left(x_{4}\right)+\alpha_{1234} \min \left(x_{3}\right) \max \left(x_{4}\right) \geq 0$,

$\alpha_{12}+\alpha_{123} \max \left(x_{3}\right)+\alpha_{124} \min \left(x_{4}\right)+\alpha_{1234} \max \left(x_{3}\right) \min \left(x_{4}\right) \geq 0$,

$\alpha_{12}+\alpha_{123} \max \left(x_{3}\right)+\alpha_{124} \max \left(x_{4}\right)+\alpha_{1234} \max \left(x_{3}\right) \max \left(x_{4}\right) \geq 0$

In case the practices take on discrete values variables (step size chosen equal to one) we replace the derivative in definition 1 by a difference. If we consider the first two practices, without loss of generality, the following definition holds:

\section{Definition 2 (discrete practices)}

Practices $x_{1}$ and $x_{2}$ are considered complementary in the function $f$ if and only if $f\left(x_{1}+1, x_{2}+1, x_{3}, \ldots, x_{n}\right)+f\left(x_{1}, x_{2}, x_{3}, \ldots, x_{n}\right) \geq f\left(x_{1}+1, x_{2}, x_{3}, \ldots, x_{n}\right)+f\left(x_{1}, x_{2}+1, x_{3}, \ldots, x_{n}\right)$ with the inequality holding strictly for at least one value of $\left(x_{1}, \ldots, x_{n}\right)$.

The case of dichotomously measured practices (practice is used or not) is a special case of this definition. In that case functions (1), (2), and (3) can be more conveniently rewritten in terms of the possible combinations of practices. With two practices the collection of possible combinations is defined in the usual binary order as $D=\{(0,0),(0,1),(1,0),(1,1)\}$. We introduce the indicator function $I_{D=(r, s)}$, equal to one when the combination is $(r, s)$, else zero. Similar collections of $D$ with corresponding indicators functions $I_{D=(r, s, t)}$ and $I_{D=(r, s, t, u)}$ are introduced for the case of three and four practices. The functions $f$ are rewritten as: 


$$
\begin{aligned}
& f\left(x_{1}, x_{2}\right)=\sum_{r=0}^{1} \sum_{s=0}^{1} \beta_{r s} I_{\left(x_{1}, x_{2}\right)=(r, s)} \\
& f\left(x_{1}, x_{2}, x_{3}\right)=\sum_{r=0}^{1} \sum_{s=0}^{1} \sum_{t=0}^{1} \beta_{r s t} I_{\left(x_{1}, x_{2}, x_{3}\right)=(r, s, t)} \\
& f\left(x_{1}, x_{2}, x_{3}, x_{4}\right)=\sum_{r=0}^{1} \sum_{s=0}^{1} \sum_{t=0}^{1} \sum_{u=0}^{1} \beta_{r s t u} I_{\left(x_{1}, x_{2}, x_{3}, x_{4}\right)=(r, s, t, u)}
\end{aligned}
$$

The conditions of complementarity now correspond to $\alpha_{12}=\beta_{11}+\beta_{00}-\beta_{10}-\beta_{01}>0$ for two practices, $\alpha_{12}=\beta_{110}+\beta_{000}-\beta_{100}-\beta_{010} \geq 0$ and $\alpha_{12}+\alpha_{123}=\beta_{111}+\beta_{001}-\beta_{101}-\beta_{011} \geq 0$ for three practices and the following four inequalities for four practices:

$$
\begin{aligned}
& \alpha_{12}=\beta_{1100}+\beta_{0000}-\beta_{1000}-\beta_{0100} \geq 0 \\
& \alpha_{12}+\alpha_{123}=\beta_{1110}+\beta_{0010}-\beta_{1010}-\beta_{0110} \geq 0 \\
& \alpha_{12}+\alpha_{124}=\beta_{1101}+\beta_{0001}-\beta_{1001}-\beta_{0101} \geq 0 \\
& \alpha_{12}+\alpha_{123}+\alpha_{124}+\alpha_{1234}=\beta_{1111}+\beta_{0011}-\beta_{1011}-\beta_{0111} \geq 0 .
\end{aligned}
$$

\section{The testing procedure}

In case of two practices the test for complementarity is a one-sided t-test of the null hypothesis of $\alpha_{12}=0$ in equation (1). However, in case of more than two practices, the number of inequality constraints that have to be tested simultaneously is $2^{n-1}$. Statistical tests of $H_{0}: R \beta=r$ versus $H_{a}: R \beta \geq r$ with $R$ having rank $k$ in the standard linear model $y=X \beta+\varepsilon$ with one of the inequalities holding strictly have been considered in Gouriéroux, Holly, and Monfort (1982). Kudô (1963, p.414) derived the theorem underlying this test. The so-called normal orthant probability, $P\{\Omega\}$, being the probability that the variables with a multivariate normal distribution with mean zero and variance-covariance matrix $\Omega=R\left(X^{\prime} X\right)^{-1} R^{\prime}$ are all positive, plays a central role in this theorem:

\section{Theorem 1 (the Kudô theorem):}

Let $\left(x_{1}, \ldots, x_{k}\right)$ have a multivariate normal distribution with mean zero and known variancecovariance matrix $\Sigma$ and let $L R=-2 \ln \lambda$ where $\lambda$ is the likelihood ratio test statistic of $H_{0}: E\left(x_{i}\right)=0$ for $i=1, \ldots, k$ versus $H_{A}: E\left(x_{i}\right) \geq 0$ for $i=1, \ldots, k$ where the inequality is strict for at 
least one value of $i$. Then $\operatorname{Pr}(L R \geq c)=\sum_{M \subseteq K} \operatorname{Pr}\left(\chi_{n(M)}^{2} \geq c\right) P\left\{\Sigma_{B}^{-1}\right\} P\left\{\Sigma_{M: B}\right\}$ where the summation runs over all the subsets $M$ of $K=\{1, \ldots, k\}$ including $\emptyset, n(M)$ is the number of elements in $M, B$ is the complement of $M$, so that $M \cap B=\varnothing$ and $M \cup B=K, \Sigma_{B}$ is the variance-covariance matrix of $x_{i}$ with $i \in B, \Sigma_{M: B}$ is the same for $x_{i}$ with $i \in M$ but under the condition that $x_{i}=0$ for $i \in B{ }^{l}$

From this theorem it follows that in case of $p$ inequality restrictions we have that the probability of $L R$ exceeding $c$ under the null hypothesis equals a mixed chi-square distribution of $\sum_{i=0}^{p} \operatorname{Pr}\left\{\chi_{i}^{2} \geq c\right\} w_{i p}$ (see also Shapiro, 1985, p.138 and Wolak, 1989, p.214). ${ }^{2}$ Therefore, the p-value equals $1-\sum_{i=0}^{p} \operatorname{Pr}\left\{\chi_{i}^{2} \geq L R\right\} w_{i p}$. Shapiro (1985) proves that the weights sum up to unity. The statistic can be compared to Table 1 from Kodde and Palm (1986) who provide critical values $\left(c_{l}\right.$ and $c_{u}$ ) for significance levels ranging in size from 0.25 to 0.001 and degrees of freedom from 1 to 40 . In case the computed value falls in the indecision region, an exact p-value must be computed. The weights for two restrictions $(n=3)$ are $w_{02}=\cos ^{-1}\left(\Omega_{12} / \sqrt{\Omega_{11} \Omega_{22}}\right) / 2 \pi$ where $\Omega_{i j}=R_{i}\left(X^{\prime} X\right)^{-1} R^{\prime}{ }_{j}$ with $R_{j}$ being the $j$ th row of $R, w_{12}=1 / 2$ and $w_{22}=1 / 2-w_{02}$ (see Shapiro, 1985). Computation of weights requires some more work for four ( $n$ is 4 ) or more restrictions. The normal orthant probability plays a central role in this computation ${ }^{3}$. The weights $w_{p p}$ and $w_{0 p}$ are equal to $P\{\Omega\}$ and $P\left\{\Omega^{-1}\right\}$, respectively, where $\Omega$ is the positive-definite covariance matrix of $\left(x_{1}, \ldots, x_{p}\right)$. Define $P=\{1, \ldots, p\}$ and $M(k)$ the subsets of $P$ of exactly $k$ elements $\left(\left(\begin{array}{l}p \\ k\end{array}\right)\right.$ in number). The weights $w_{k p}$ where $k=1, \ldots, p-1$ are then as follows:

$w_{k p}=\sum_{M(k) \subseteq P} P\left\{\Omega_{M(k), 11}-\Omega_{M(k), 12} \Omega_{M(k), 22}^{-1} \Omega_{M(k), 21}\right\} P\left\{\Omega_{M(k), 22}^{-1}\right\}$

\footnotetext{
${ }^{1}$ For the empty set $M=\varnothing$ we have that $\chi_{n(M)}^{2}=\chi_{0}^{2}$ is a constant zero and $P\left\{\Sigma_{M}^{-1}\right\}=P\left\{\Sigma_{M: K}\right\}=1$

${ }^{2}$ Because $\operatorname{Pr}\left\{\chi_{0}^{2} \geq a\right\}=0$ for all $a$, the summation could also run from 1 up till $p$. In empirical applications the variance-covariance matrix has to be estimated and the mixed chi-square distribution only holds asymptotically.

${ }^{3}$ Several methods are available for numerical computation of the multivariate normal integral, see e.g. Sun (1988b), Genz (1993) and Hajivassiliou et al. (1996).
} 
where $\Omega_{M(k), 11}$ is the $k x k$-matrix obtained from $\Omega$ after only keeping the rows and columns corresponding to the elements of $M(k), \Omega_{M(k), 12}$ is the $k \mathrm{x}(p-k)$-matrix obtained from $\Omega$ after keeping the rows corresponding to the elements of $M(k)$ and the columns corresponding to all the elements of $P$ that are not in $M(k), \Omega_{M(k), 21}$ is the $(p-k) \mathrm{x} k$-matrix obtained from $\Omega$ after keeping the rows corresponding to all the elements of $P$ that are not in $M(k)$ and the columns corresponding to the elements of $M(k)$, and $\Omega_{M(k), 22}$ is the $(p-k) x(p-k)$-matrix obtained from $\Omega$ after keeping the rows and columns corresponding to all the elements of $P$ that are not in $M(k)$.

We illustrate (7) for the case of four practices and, hence, $p$ equal to 4 . For four practices we have that $w_{24}=1-w_{04}-w_{14}-w_{34}-w_{44}$ where $w_{14}$ and $w_{34}$ are as follows: ${ }^{4}$

$$
\begin{aligned}
w_{14}= & P\left\{\sigma_{11}\right\} P\left\{\left(\begin{array}{lll}
\sigma_{22} & \sigma_{23} & \sigma_{24} \\
\sigma_{23} & \sigma_{33} & \sigma_{34} \\
\sigma_{24} & \sigma_{34} & \sigma_{44}
\end{array}\right)^{-1}\right\}+P\left\{\sigma_{22}\right\} P\left\{\left(\begin{array}{lll}
\sigma_{11} & \sigma_{13} & \sigma_{14} \\
\sigma_{31} & \sigma_{33} & \sigma_{34} \\
\sigma_{41} & \sigma_{43} & \sigma_{44}
\end{array}\right)^{-1}\right\} \\
& +P\left\{\left(\sigma_{33}\right\} P\left\{\left(\begin{array}{lll}
\sigma_{11} & \sigma_{12} & \sigma_{14} \\
\sigma_{21} & \sigma_{22} & \sigma_{24} \\
\sigma_{41} & \sigma_{42} & \sigma_{44}
\end{array}\right)^{-1}\right\}+P\left\{\sigma_{44}\right\} P\left\{\begin{array}{lll}
\sigma_{11} & \sigma_{12} & \sigma_{13} \\
\sigma_{21} & \sigma_{22} & \sigma_{23} \\
\sigma_{31} & \sigma_{32} & \sigma_{33}
\end{array}\right)^{-1}\right\} \\
w_{34}= & P\left\{\left(\begin{array}{lll}
\sigma_{11} & \sigma_{12} & \sigma_{13} \\
\sigma_{21} & \sigma_{22} & \sigma_{23} \\
\sigma_{41} & \sigma_{32} & \sigma_{33}
\end{array}\right)-\left(\begin{array}{l}
\sigma_{14} \\
\sigma_{24} \\
\sigma_{34}
\end{array}\right)\left(\begin{array}{l}
\sigma_{14} \\
\sigma_{24} \\
\sigma_{34}
\end{array}\right)^{\mathrm{T}} / \sigma_{44}\right\} P\left\{\sigma_{44}^{-1}\right\}+P\left\{\left(\begin{array}{lll}
\sigma_{11} & \sigma_{12} & \sigma_{13} \\
\sigma_{21} & \sigma_{22} & \sigma_{23} \\
\sigma_{41} & \sigma_{32} & \sigma_{33}
\end{array}\right)-\left(\begin{array}{l}
\sigma_{14} \\
\sigma_{24} \\
\sigma_{34}
\end{array}\right)\left(\begin{array}{l}
\sigma_{41} \\
\sigma_{42} \\
\sigma_{43}
\end{array}\right)^{\mathrm{T}} / \sigma_{33}\right\} P\left\{\sigma_{33}^{-1}\right\} \\
+ & P\left\{\left(\begin{array}{lll}
\sigma_{11} & \sigma_{13} & \sigma_{14} \\
\sigma_{31} & \sigma_{33} & \sigma_{34} \\
\sigma_{41} & \sigma_{43} & \sigma_{44}
\end{array}\right)-\left(\begin{array}{l}
\sigma_{21} \\
\sigma_{32} \\
\sigma_{42}
\end{array}\right)\left(\begin{array}{l}
\sigma_{12} \\
\sigma_{23} \\
\sigma_{24}
\end{array}\right)^{\mathrm{T}} / \sigma_{22}\right\} P\left\{\sigma_{22}^{-1}\right\}+P\left\{\left(\begin{array}{lll}
\sigma_{22} & \sigma_{23} & \sigma_{24} \\
\sigma_{32} & \sigma_{33} & \sigma_{34} \\
\sigma_{42} & \sigma_{43} & \sigma_{44}
\end{array}\right)-\left(\begin{array}{l}
\sigma_{21} \\
\sigma_{31} \\
\sigma_{41}
\end{array}\right)\left(\begin{array}{l}
\sigma_{12} \\
\sigma_{13} \\
\sigma_{14}
\end{array}\right)^{\mathrm{T}} / \sigma_{11}\right\} P\left\{\sigma_{11}^{-1}\right\}
\end{aligned}
$$

\section{Empirical applications}

To illustrate the method we present two empirical applications. In example 1, we estimate a labor productivity equation including three (broad) innovation strategies. In a second example, we estimate

${ }^{4}$ In practice $w_{24}$ is computed as $w_{24}=\sum_{i=1}^{3} \sum_{j=i+1}^{4} q_{i j}$ where $q_{i j}=P\left\{\Omega_{M(k), i i}-\Omega_{M(k), i j} \Omega_{M(k), j j}^{-1} \Omega_{M(k), j i}\right\} P\left\{\Omega_{M(k), j j}^{-1}\right\}$ and then using the summation of all weights to unity as a check of correct computation 
a labor productivity equation including four types of $R \& D$ cooperation practices. In both cases the practices are dichotomous, hence we include sets of mutually exclusive dummies $D$. Our data come from two consecutive Community Innovation Surveys among Dutch firms for the years of 1996 and 1998 (source: Statistics Netherlands). The performance variable is labor productivity in 1998. The independent variables include the innovation strategies as well as firm size, R\&D intensity, and labor productivity in 1996. All independent variables are taken from the 1996 survey to reduce possible simultaneity between the decision variables and the output measure.

Example one considers the impact of three innovation strategies that can be pursued simultaneously or exclusively: (1) product innovation, (2) process innovation, and (3) organizational innovation that is manifested through reorganization or implementation of new marketing and management practices. The constructed vector $D$ thus includes eight elements. The results of the unconstrained estimation and the estimation under the alternative hypotheses are reported in Table $1 .{ }^{5}$

[Table 1 is about here]

In the first step the model is estimated three times, once unconstrained, once imposing less or equal restrictions, and once imposing greater or equal restrictions. In the second step, the constrained model that produced the highest log-likelihood value in the first step (the model for which the imposition of the inequality restrictions are least objectionable) is tested against the equality restricted alternative using the LR test. In the first step, we compare the log-likelihood values of the inequality constrained models with the unrestricted loglikelihood value. This suggests to test for substitutability in case of product \& process innovation, and complementarity in the cases of product \& organizational innovation and process $\&$ organizational innovation. In the second step the loglikelihood ratio tests show that we cannot reject the null hypothesis of no substitutability in the product \& process innovation case, nor can we reject the null of no complementarity in the process \& organizational innovation case. As can be seen from the table, neither is significant at 10 percent level. The secondstep result does reveal a complementary relationship between process and organizational innovation: the LR test against the null of no complementarity is rejected, the value 14.6106 being greater than the critical value $c_{u}$ (the calculated $p$-value is 0.0002 ). The result supports the notion that process innovations are more effective if accompanied by necessary changes in organizational practices ${ }^{6}$.

\footnotetext{
${ }^{5}$ The full results are available from the authors upon request. Further details on the data are available in Belderbos et al. (2003).

${ }^{6}$ In Table A2 in the appendix we present the results obtained from a similarly specified model by simply interacting pairs of (dummy variable) strategies. A simple t-test performed on these interaction terms reveals an additional significant relationship in our sample, i.e. between process and product innovation. More generally, a procedure that relies on a t-test on an interaction dummy may lead to some misleading conclusions especially
} 
To illustrate the case of four practices, we examine the impact of four types of R\&D cooperation strategies: (1) cooperation with customers, (2) cooperation with suppliers, (3) cooperation with competitors, and (4) cooperation with government institutions (research centers and universities). The constructed vector $D$ thus includes 16 elements. For each pair we impose four inequalities described in section 2. The results of the unconstrained estimation and the estimation under the alternative hypothesis are reported in Table 2.

[Table 2 is about here]

The practices customer \& supplier cooperation and customer $\&$ institutional cooperation display no evidence of complementarity or substitutability because their corresponding LR test statistics are less than the tabulated value. Similarly, the null of no substitutability cannot be rejected for the practices supplier \& institutional cooperation. The second-step test of substitutability between the practices customer \& competitor cooperation, supplier \& competitor cooperation, and competitor \& institutional cooperation against the null of no substitutability relationship effectively establishes them as substitutes at the 1 percent, 10 percent, and 10 percent significance level, respectively. This result indicates that cooperation with rivals is less efficient in case it is accompanied by other R\&D partnerships.

\section{Conclusion}

This paper develops a test for complementarity and substitutability using an output function approach in which organizational practices affect performance. The testing procedure uses a structural estimation framework and applies inequality constrained least squares estimation. The analytical solution is given for the general case and demonstrated for three and four practices. We note that recent work (Athey and Stern, 2002; Bresnahan et al, 2002) has drawn conclusions on complementarity based on inadequate testing methods. With empirical studies of complementarity gaining prominence in a number of economics and management domains, the proposed framework should make adequate testing for complementarity more accessible for applied researchers. We also note that the proposed test is equivalently applicable for testing for super- and submodularity of the objective function in organizational design practices (e.g. Milgrom and Roberts, 1990). As shown in Topkis (1998), it is sufficient to check the pair-wise inequalities in case there are more than two

when opposing effects (some pairs being complements and some pairs are substitutes) are present among the strategies. 
dimensions in the lattice. Hence, in case all pair-wise relations satisfy complementarity, the objective function is supermodular. Thus, in our first example, the test satisfies the requirements for supermodularity of the objective function in product, process and organizational innovation practices.

\section{References}

Arora, A. 1996. Testing for compementarities in reduced-form regressions: a note. Economics Letters $50: 51-5$.

Arora, A. and A. Gambardella. 1990. Complementarity and external linkages: the strategies of the large firms in biotechnology. Journal of Industrial Economics 38: 361-79.

Athey, S. and S. Stern. 1998. An empirical framework for testing theories about complementarity in organizational design. NBER working paper \#6600.

Athey, S. and S. Stern. 2002. The impact of information technology on emergency health care outcomes. RAND Journal of Economics 33(3): 399-432.

Baumol, W., J. C. Panzar, and R. D. Willig. 1988. Contestable Markets and the Theory of Industry Structure. Harcourt Brace Jovanovich.

Belderbos, R., M. Carree, B. Diederen, B. Lokshin, R. Veugelers. 2003. Heterogeneity in R\&D cooperation strategies. CEPR Discussion paper 4021.

Bresnahan, T., E. Brynjolfsson, and L. M. Hit, 2002, Information Technology, Workplace Organization, and the Demand for Skilled Labor: Firm-Level Evidence, Quarterly Journal of Economics 117, Feb 2002, 339-75.

Caroli, E. and J. Van Reenen, 2001, Skill-biased organizational change? Evidence from a panel of British and French establishments. Quarterly Journal of Economics 116, Nov. 2001: 1449-1492. 
Genz, A. 1993. Comparison of methods for the computation of multivariate normal probabilities Computing Science and Statistics 25: 400-05.

Gouriéroux, C., A. Holly, and A. Monfort. 1982. Likelihood ratio test, Wald test, and Kuhn-Tucker test in linear models with inequality constraints on the regression parameters. Econometrica 50(1): 6380.

Hajivassiliou, Vassilis, Daniel McFadden, and Paul Ruud. (1996). Simulation of multivariate normal rectangle probabilities and their derivatives: Theoretical and computational results. Journal of Econometrics 72: 85-134.

Ichniowski, C., K. Shaw, and G. Prennushi. 1997. The effects of human resource management practices on productivity. American Economic Review 87: 291-313.

Kodde, D. and F. Palm. 1986. Wald criteria for jointly testing equality and inequality restrictions. Econometrica 54(5): 1243-48.

Kudô, A. 1963. A multivariate analogue of the one-sided test. Biometrika 50: 403-18.

Shapiro, A. 1985. Asymptotic distribution of test statistics in the analysis of moment structures under inequality consraints. Biometrika 72(1): 133-44.

Shapiro, A. 1987. A conjecture related to chi-bar-squared distributions. American Mathematical Monthly 94: 46-48.

Milgrom, P. and J. Roberts. 1990. The economics of modern manufacturing: technology, strategy, and organization. American Economic Review 80: 511-28.

Milgrom, P. and J. Roberts. 1995. Complementarities and fit: Strategy, structure and organizational change in manufacturing. Journal of Accounting and Economics 19: 179-208.

Mohnen, P. and L-H. Röller. 2001. Complementarities in innovation policy. CEPR Discussion Paper 2712. 
Sun, H-J. 1988. A General reduction method for n-variate normal orthant probability. Communication in Statistical-Theoretical Methods 17(11): 3913-21.

Topkis, D. 1998. Supermodularity and Complimentarity. Princeton University Press.

Veugelers, R., and B. Cassiman. 2003. Complementarity in the innovation strategy: Internal R\&D, external technology acquisition, and cooperation in R\&D. Mimeo, Katholieke Universiteit Leuven.

Wolak, F. 1989. Testing inequality constraints in linear econometric models. Journal of Econometrics 41: 205-35.

Wolak, F. 1991. The local nature of hypothesis tests involving inequality constraints in nonlinear models. Econometrica 59: 981-95. 
Table 1. Unconstrained and constrained models, 3 practices

\begin{tabular}{|c|c|c|c|c|c|c|}
\hline & & Complementarity & Substitutability & & & \\
\hline & Unconstrained & $\begin{array}{l}\text { Inequality } \\
\text { constrained } \geq\end{array}$ & $\begin{array}{l}\text { Inequality } \\
\text { constrained } \leq\end{array}$ & $\begin{array}{l}\text { Equality } \\
\text { constrained }\end{array}$ & LR Test & p-value \\
\hline Product and Process innovation & -532.4561 & -533.3122 & -532.4565 & -533.3125 & 1.7121 & 0.1923 \\
\hline Product and Organizational innovation & -532.4561 & -532.4561 & -533.0319 & -533.0319 & 1.1516 & 0.2772 \\
\hline Process and Organizational innovation & -532.4561 & -532.4561 & -539.7614 & -539.7614 & $14.6106 * * *$ & 0.0002 \\
\hline
\end{tabular}

Note: LR tests the value in italics against the equality constrained alternative. The number of restrictions $(p)$ is two. The superscripts $*, * *$ and $* * *$ indicate significance at $10 \%, 5 \%$ and $1 \%$ respectively. For $\alpha=.05, \mathrm{c}_{1}=2.706$ and $\mathrm{c}_{\mathrm{u}}=5.138$. For $\alpha=.01, \mathrm{c}_{\mathrm{l}}=5.412$ and $\mathrm{c}_{\mathrm{u}}=8.273$.

Table 2. Unconstrained and constrained models, 4 practices

\begin{tabular}{|c|c|c|c|c|c|c|}
\hline & & Complementarity & Substitutability & & & \\
\hline & Unconstrained & $\begin{array}{l}\text { Inequality } \\
\text { constrained } \geq\end{array}$ & $\begin{array}{l}\text { Inequality } \\
\text { constrained } \leq\end{array}$ & $\begin{array}{l}\text { Equality } \\
\text { constrained }\end{array}$ & LR Test & p-value \\
\hline Customers and suppliers (1\&2) & -634.9342 & -635.5136 & -635.9985 & -636.5778 & 2.1282 & 0.3454 \\
\hline Customers and competitors $(1 \& 3)$ & -634.9342 & -640.9378 & -635.3019 & -641.3021 & $12.0004 * * *$ & 0.0041 \\
\hline Customers and institutional cooperation $(1 \& 4)$ & -634.9342 & -635.1970 & -636.5791 & -636.8420 & 3.2900 & 0.2081 \\
\hline Suppliers and competitors $(2 \& 3)$ & -634.9342 & -638.1098 & -635.0537 & -638.2276 & $6.3478^{*}$ & 0.0535 \\
\hline Suppliers and institutional cooperation $(2 \& 4)$ & -634.9342 & -635.5159 & -635.0625 & -635.6421 & 1.1593 & 0.5238 \\
\hline Competitors and institutional cooperation $(3 \& 4)$ & -634.9342 & -637.8096 & -635.0905 & -637.9640 & $5.7472 *$ & 0.0701 \\
\hline
\end{tabular}

respectively. For $\alpha=.10, c_{1}=1.642$ and $c_{u}=7.094$. For $\alpha=.05, c_{1}=2.706$ and $c_{\mathrm{u}}=8.761$. For $\alpha=.01, c_{1}=5.412$ and $c_{\mathrm{u}}=12.483$. 
Appendix 1 (for referees)

Table A1. Unconstrained OLS results from examples one and two.

\begin{tabular}{|c|c|c|}
\hline \multicolumn{3}{|c|}{ Dependent: $\log ($ Value added per employee, 1998$)$} \\
\hline & $(1)$ & $(2)$ \\
\hline \multicolumn{3}{|l|}{ Lagged variables } \\
\hline Log(Employment, 1996) & $\begin{array}{l}0.0802 \\
(0.0118)\end{array}$ & $\begin{array}{l}0.0826 \\
(0.0104)\end{array}$ \\
\hline R\&D intensity, 1996 & $\begin{array}{l}0.2566 \\
(0.2493)\end{array}$ & $\begin{array}{l}0.3031 \\
(0.2046)\end{array}$ \\
\hline Log(Value added per employee, 1996) & $\begin{array}{l}0.3562 \\
(0.2331)\end{array}$ & $\begin{array}{l}0.3744 \\
(0.0206)\end{array}$ \\
\hline \multicolumn{3}{|l|}{ State dummies } \\
\hline $\begin{array}{l}\text { (1) product, process, org. innovation: no, no, no } \\
\text { (2) customers, suppliers, competitors, institutions: no, no, no, no }\end{array}$ & $\begin{array}{l}2.6772 \\
(0.1079)\end{array}$ & $\begin{array}{l}2.4943 \\
(0.0892)\end{array}$ \\
\hline $\begin{array}{l}\text { (1) product, process, org. innovation: no, no, yes } \\
\text { (2) customers, suppliers, competitors, institutions: no, no, no, yes }\end{array}$ & $\begin{array}{l}2.4528 \\
(0.1038)\end{array}$ & $\begin{array}{l}2.5570 \\
(0.1184)\end{array}$ \\
\hline $\begin{array}{l}\text { (1) product, process, org. innovation: no, yes, no } \\
\text { (2) customers, suppliers, competitors, institutions: no, no, yes, no }\end{array}$ & $\begin{array}{l}2.6947 \\
(0.1255)\end{array}$ & $\begin{array}{l}2.6101 \\
(0.1147)\end{array}$ \\
\hline $\begin{array}{l}\text { (1) product, process, org. innovation: no, yes, yes } \\
\text { (2) customers, suppliers, competitors, institutions: no, no, yes, yes }\end{array}$ & $\begin{array}{l}2.5890 \\
(0.1139)\end{array}$ & $\begin{array}{l}2.4795 \\
(0.1284)\end{array}$ \\
\hline $\begin{array}{l}\text { (1) product, process, org. innovation: yes, no, no } \\
\text { (2) customers, suppliers, competitors, institutions: no, yes, no, no }\end{array}$ & $\begin{array}{l}2.5746 \\
(0.1018)\end{array}$ & $\begin{array}{l}2.5355 \\
(0.1056) \\
\end{array}$ \\
\hline $\begin{array}{l}\text { (1) product, process, org. innovation: yes, no, yes } \\
\text { (2) customers, suppliers, competitors, institutions: no, yes, no, yes }\end{array}$ & $\begin{array}{l}2.6054 \\
(0.1027)\end{array}$ & $\begin{array}{l}2.6479 \\
(0.1221)\end{array}$ \\
\hline $\begin{array}{l}\text { (1) product, process, org. innovation: yes, yes, no } \\
\text { (2) customers, suppliers, competitors, institutions: no, yes, yes, no }\end{array}$ & $\begin{array}{l}2.5948 \\
(0.1062)\end{array}$ & $\begin{array}{l}2.5403 \\
(0.2437)\end{array}$ \\
\hline $\begin{array}{l}\text { (1) product, process, org. innovation: yes, yes, yes } \\
\text { (2) customers, suppliers, competitors, institutions: no, yes, yes, yes }\end{array}$ & $\begin{array}{l}2.6371 \\
(0.1026)\end{array}$ & $\begin{array}{l}2.1610 \\
(0.1373)\end{array}$ \\
\hline (2) customers, suppliers, competitors, institutions: yes, no, no, no & & $\begin{array}{l}2.5040 \\
(0.1055)\end{array}$ \\
\hline (2) customers, suppliers, competitors, institutions: yes, no, no, yes & & $\begin{array}{l}2.5104 \\
(0.1325)\end{array}$ \\
\hline (2) customers, suppliers, competitors, institutions: yes, no, yes, no & & $\begin{array}{l}2.4536 \\
(0.1949)\end{array}$ \\
\hline (2) customers, suppliers, competitors, institutions: yes, no, yes, yes & & $\begin{array}{l}2.5883 \\
(0.1486)\end{array}$ \\
\hline (2) customers, suppliers, competitors, institutions: yes, yes, no, no & & $\begin{array}{l}2.4641 \\
(0.1082)\end{array}$ \\
\hline (2) customers, suppliers, competitors, institutions: yes, yes, no, yes & & $\begin{array}{l}2.5051 \\
(0.1196)\end{array}$ \\
\hline (2) customers, suppliers, competitors, institutions: yes, yes, yes, no & & $\begin{array}{l}2.5191 \\
(0.1196)\end{array}$ \\
\hline (2) customers, suppliers, competitors, institutions: yes, yes, yes, yes & & $\begin{array}{l}2.5226 \\
(0.1094)\end{array}$ \\
\hline Number of observations & 1050 & 1364 \\
\hline $\mathrm{F}$ & 46.09 & 35.03 \\
\hline LL & -532.4561 & -634.9342 \\
\hline
\end{tabular}

Standard errors are in parentheses. Columns (1) and (2) are the unconstrained estimates of the model in examples one and two, respectively. Full sets of estimates are available from the authors upon request. $R \& D$ intensity is the ratio of the $R \& D$ personnel to total personnel. Size is measured as the logarithm of the total number of employees. Inclusion of the industry dummies produces estimates very close to the ones reported. 
Table A2. Complementarity results from example one, obtained by interacting dummies.

\begin{tabular}{|l|l|l|l|l|}
\hline \multicolumn{5}{|c|}{ Dependent: $\log ($ Value added per employee, 1998) } \\
\hline & \multicolumn{1}{|c|}{$(1)$} & \multicolumn{1}{c|}{$(2)$} & \multicolumn{1}{c|}{$(4)$} \\
\hline & & & & \\
\hline Log(Employment) ${ }_{-1}$ & 0.0840 & 0.0833 & 0.0826 & 0.0839 \\
& $(0.0150)$ & $(0.0151)$ & $(0.0150)$ & $(0.0151)$ \\
\hline R\&D intensity ${ }_{-1}$ & 0.2918 & 0.2872 & 0.2741 & 0.2988 \\
& $(0.2440)$ & $(0.2447)$ & $(0.2452)$ & $(0.2472)$ \\
\hline Log(Value added per employee) $)_{-1}$ & 0.3570 & 0.3562 & 0.3571 & 0.3588 \\
& $(0.0685)$ & $(0.0688)$ & $(0.0690)$ & $(0.0687)$ \\
\hline Product innovation & 0.0004 & 0.0390 & -0.0300 & 0.0125 \\
& $(0.0401)$ & $(0.0281)$ & $(0.3797)$ & $(0.0252)$ \\
\hline Process innovation & 0.0345 & 0.1162 & 0.03456 & -0.0500 \\
& $(0.0527)$ & $(0.0537)$ & $(0.0326)$ & $(0.0434)$ \\
\hline Organizational innovation & -0.0671 & -0.0195 & -0.0512 & -0.0427 \\
& $(0.0374)$ & $(0.0272)$ & $(0.0361)$ & $(0.0299)$ \\
\hline Product*Process innovation & -0.1627 & -0.1456 & & \\
& $(0.0680)$ & $(0.0671)$ & & \\
\hline Product*Organizational innovation & 0.0663 & & 0.0763 & \\
& $(0.0487)$ & & $(0.0489)$ & \\
\hline Process*Organizational innovation & 0.1423 & & & 0.1396 \\
& $(0.0605)$ & & & $(0.0596)$ \\
\hline Observations & 1050 & 1050 & 1050 & 1050 \\
\hline $\mathrm{R}^{2}$ & 0.301 & 0.406 & 0.407 & 0.406 \\
\hline
\end{tabular}

Standard errors are in parentheses. R\&D intensity is the ratio of the R\&D personnel to total personnel. Size is measured as the logarithm of the total number of employees.

Table A3. Descriptive Statistics for the sample used in first example

\begin{tabular}{|c|c|c|}
\hline & Mean & S.D \\
\hline Log(Value added/employee) & 4.578 & 0.483 \\
\hline 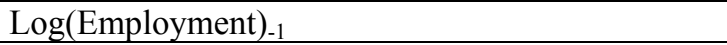 & 4.610 & 1.168 \\
\hline R\&D intensity ${ }_{-1}$ & 0.033 & 0.051 \\
\hline Log(Value added/employee $)_{-1}$ & 4.501 & 0.579 \\
\hline product, process, org. innovation: no, no, no & 0.073 & 0.261 \\
\hline product, process, org. innovation: no, no, yes & 0.109 & 0.311 \\
\hline product, process, org. innovation: no, yes, no & 0.028 & 0.164 \\
\hline product, process, org. innovation: no, yes, yes & 0.044 & 0.205 \\
\hline product, process, org. innovation: yes, no, no & 0.182 & 0.386 \\
\hline product, process, org. innovation: yes, no, yes & 0.207 & 0.405 \\
\hline product, process, org. innovation: yes, yes, no & 0.130 & 0.336 \\
\hline product, process, org. innovation: yes, yes, yes & 0.229 & 0.420 \\
\hline
\end{tabular}


Table A4. Descriptive Statistics for the sample used in second example

\begin{tabular}{|l|l|l|}
\hline & Mean & S.D \\
\hline Log(Value added/employee) & 4.563 & 0.467 \\
\hline Log(Employment)-1 & 4.478 & 1.144 \\
\hline R\&D intensity-1 & 0.032 & 0.052 \\
\hline Log(Value added/employee)-1 $_{\text {customers, suppliers, competitors, institutions: no, no, no, no }}$ & 4.492 & 0.550 \\
\hline customers, suppliers, competitors, institutions: no, no, no, yes & 0.691 & 0.462 \\
\hline customers, suppliers, competitors, institutions: no, no, yes, no & 0.023 & 0.151 \\
\hline customers, suppliers, competitors, institutions: no, no, yes, yes & 0.023 & 0.146 \\
\hline customers, suppliers, competitors, institutions: no, yes, no, no & 0.014 & 0.117 \\
\hline customers, suppliers, competitors, institutions: no, yes, no, yes & 0.041 & 0.198 \\
\hline customers, suppliers, competitors, institutions: no, yes, yes, no & 0.021 & 0.142 \\
\hline customers, suppliers, competitors, institutions: no, yes, yes, yes & 0.002 & 0.047 \\
\hline customers, suppliers, competitors, institutions: yes, no, no, no & 0.011 & 0.104 \\
\hline customers, suppliers, competitors, institutions: yes, no, no, yes & 0.014 & 0.198 \\
\hline customers, suppliers, competitors, institutions: yes, no, yes, no & 0.004 & 0.117 \\
\hline customers, suppliers, competitors, institutions: yes, no, yes, yes & 0.009 & 0.060 \\
\hline customers, suppliers, competitors, institutions: yes, yes, no, no & 0.033 & 0.093 \\
\hline customers, suppliers, competitors, institutions: yes, yes, no, yes & 0.023 & 0.179 \\
\hline customers, suppliers, competitors, institutions: yes, yes, yes, no & 0.010 & 0.151 \\
\hline customers, suppliers, competitors, institutions: yes, yes, yes, yes & 0.040 & 0.101 \\
\hline
\end{tabular}

\section{Appendix 2 (for referees)}

Table A5 presents the results of the test of the accuracy of the computation of $w_{i p}$ for the case $\mathrm{p}=4$. Column (1) contains the results from the analytical formulae in Shapiro (1985), column (2) contains results obtained with the GHK-simulator (average of 100 simulations with 2000 draws each) and column (3) contains results obtained by the Sun (1988)-routine. The latter produces the most accurate weights, but the GHK-simulator approximations are also quite accurate. In the paper we use the Sun (1988)-routine.

Table A5. Computation of the weights in case of four practices

\begin{tabular}{|c|c|c|c|}
\hline & $(1)$ & $(2)$ & $(3)$ \\
\hline$w_{04}$ & Not available & 0.05010065 & 0.05012682 \\
\hline$w_{14}$ & 0.22438424 & 0.22437235 & 0.22438429 \\
\hline$w_{24}$ & 0.37422139 & 0.37423933 & 0.37422140 \\
\hline$w_{34}$ & 0.27561575 & 0.27560382 & 0.27561571 \\
\hline$w_{44}$ & Not available & 0.07566484 & 0.07565178 \\
\hline
\end{tabular}

